\title{
Endogenous leukemia inhibitory factor attenuates endotoxin response
}

\author{
Marietta A Weber ${ }^{1}$, Silvia Schnyder-Candrian², Bruno Schnyder², Valerie Quesniaux ${ }^{2}$, \\ Valeria Poli ${ }^{3}$, Colin L Stewart ${ }^{1}$ and Bernhard Ryffel ${ }^{2}$ \\ ${ }^{1}$ Cancer and Developmental Biology Laboratory, NCI-FCRDC, Frederick, MD, USA; ${ }^{2} C N R S$, Orléans, France \\ and ${ }^{3}$ Dipartimento di Genetica, Biologia e Biochimica, Universita' di Torino, Italy
}

\begin{abstract}
Leukemia inhibitory factor (LIF) is induced in inflammation and likely plays a regulatory role. Using LIF-deficient mice (LIF-I-), we report here that endogenous LIF has a protective role in endotoxic shock and host defence. LIF-I- mice have heightened sensitivity to LPS in a LPS/D-galactosamine (D-Gal) sensitization model compared to wild-type mice (LIF $+I+$ ), enhanced thrombocytopenia and leukopenia, with increased hepatic necrosis, neutrophil sequestration in the lung and accelerated mortality. These findings correlated with 10 -fold higher tumour necrosis factor- $\alpha$ (TNF $\alpha$ ) and interleukin-6 (IL-6) serum levels and reduced IL-10 production in LIF-Imice in response to LPS. Therefore, endogenous LIF attenuates the endotoxic shock response, enhances the expression of basal acute phase proteins and IL-10 production, which downregulates TNF $\alpha$ synthesis and release and thereby confers partial protection to endotoxemia.
\end{abstract}

Laboratory Investigation (2005) 85, 276-284, advance online publication, 20 December 2004; doi:10.1038/labinvest.3700216

Keywords: LPS; LIF-deficient mice; endotoxic shock; LIF; TNF; IL-6, acute phase

Leukaemia inhibitory factor (LIF) is a secreted cytokine with pleiotropic functions, which include the inhibition of adipogenesis, neuronal and stem cell survival, induction of the acute-phase response proteins and embryo implantation. ${ }^{1}$ LIF, like tumour necrosis factor alpha $(\mathrm{TNF} \alpha)$, interleukin-1 (IL-1) and IL-6, is involved in mediating aspects of the inflammatory response such as stimulation of acute-phase protein (APP) synthesis, induction of cachexia and inhibition of lipoprotein lipase (LPL) activity $^{2}$ and hypothalamic pituitary adrenal axis responses. $^{3}$ A partial functional redundancy of LIF with IL-6, IL-11, ciliary neutrotrophic factor (CNTF) and oncostatin M (OSM) is due to the fact that all these ligands utilize the common receptor subunit gp130, together with their specific receptors. ${ }^{4-6}$ LIF can be induced by TNF $\alpha$, IL-1 and LPS, and is expressed by a variety of cell types in vitro, including fibroblasts, activated T cells, monocytes, macrophages, bone marrow stromal cells, astrocytes and endothelial cells, as well as by a number of tissues in adults., ${ }^{4,7}$ Clinical studies demonstrated that serum concentrations of LIF are elevated in patients with Gram-negative and menin-

Correspondence: Dr B Ryffel, MD, CNRS, 3b rue de la Ferrollerie, GEM2358, Orléans, France.

E-mail: bryffel@cnrs-orelans.fr

Received 31 March 2004; revised and accepted 20 October 2004; published online 20 December 2004 gococcal septic shock ${ }^{8}$ and that the levels correlated with the severity of disease. ${ }^{9}$ In murine endotoxic shock models LIF is induced after intraperitoneal administration of LPS 10, where it can be detected in circulation after $1-3 \mathrm{~h}^{10,11}$ LIF given prior to a lethal challenge to LPS ${ }^{12}$ or to live Escherichia coli $^{11}$ provided nearly complete resistance to these agents. Furthermore, LIF coinjected with LPS into the rat trachea decreased LPS neutrophil recruitment. ${ }^{13}$ A recent study demonstrated that LIF has an anti-inflammatory role in cutaneous inflammation using a LIF adenoviral vector, while inflammation was increased in LIF-deficient mice. ${ }^{14}$ In contrast, Block et $a l^{15}$ reported that neutralization of LIF by the administration of rabbit IgG prevented LPS-induced lethality and cytokine release in mice.

Here, we used LIF-deficient mice ${ }^{16}$ to elucidate the role of LIF in the cytokine network regulating the response to endotoxic shock. Endotoxic shock was elicited by LPS in the presence or absence of Dgalactosamine (D-Gal) sensitization. ${ }^{7,17-19}$ Our results reveal that LIF-deficient mice are more sensitive to LPS-mediated shock. This is associated with a diminution in the basal expression of APP, reduced IL-10 production together with prolonged elevation of TNF $\alpha$ and IL-6, suggesting that LIF may have an important role in mitigating the endotoxic shock response by inhibition of $\mathrm{TNF} \alpha$ and IL-6 synthesis and release. 


\section{Materials and methods}

\section{Animals}

In all, 10- to 20-week-old mice on a Balb/c background (both $\mathrm{LIF}+/+$ and LIF-/-) were produced by the team of Dr Stewart and in few additional and confirmatory experiments from Dr Brulet ${ }^{16,20}$ and maintained in a barrier animal facility. The animals were housed in $12 \mathrm{~h}$ light/dark cycles and received food and water ad libitum.

\section{Reagents}

LPS from E. coli (serotype 0111:B4) and D-Gal were purchased from Sigma (St Louis, MO, USA) and dissolved in pyrogen-free sterile saline (Abbott Lab., IL, USA). Recombinant LIF was purchased from EMD Biosciences, San Diego, CA, USA.

\section{Experimental Protocol}

Mice weighing about $25 \mathrm{~g}$ were injected intraperitoneally with either LPS alone (1 and $10 \mu \mathrm{g}$ ) or LPS (100, 10 and $1 \mathrm{ng}$ ) in combination with D-Gal (20 mg) in saline. Blood was collected from the retro-orbital sinus into EDTA-coated tubes for haematology or into heparinized tubes for blood plasma 1-2 days prior to LPS administration for baseline values and at 1,6 , and $24 \mathrm{~h}$ after LPS challenge and plasma was frozen at $-20^{\circ} \mathrm{C}$ until further processing. Body weight, clinical signs and mortality were recorded at regular intervals. Plasma aminotransferases were measured on a Cobas Fara Analyzer (Hoffmann-La Roche Inc.). Further, mice were injected recombinant LIF 6 and $1 \mathrm{~h}$ by the subcutaneous route (s.c.) prior to LPS/D-Gal challenge to test whether exogenous LIF could confer protection and/or reverse toxicity in and LIF-/- mice.

\section{Primary Macrophage Cultures}

Murine bone marrow cells were isolated from femurs from $\mathrm{LIF}+/+$ and $\mathrm{LIF}-/-$ mice and cultivated $\left(10^{6} / \mathrm{ml}\right)$ for 7 days in Dulbecco's minimal essential medium (DMEM) supplemented with $2 \mathrm{mM}$ L-glutamine and $2 \times 10^{-5} \mathrm{M} \beta$-mercaptoethanol, 20\% horse serum and 30\% L929 cell-conditioned medium (as source of M-CSF) yielding a cell culture containing more than 95\% macrophages. ${ }^{21}$ The bone marrow-derived macrophages (BMDM) were plated in 96-well microculture plates at a density of $10^{5}$ cells/well in DMEM supplemented with $2 \mathrm{mM}$ L-glutamine and $2 \times 10^{-5} \mathrm{M} \beta$-mercaptoethanol and stimulated with $100 \mathrm{ng} / \mathrm{ml}$ LPS ( $E$. coli, serotype O111:B4, Sigma). After 6 to $24 \mathrm{~h}$ of stimulation, the supernatants were harvested and analysed immediately or stored at $-20^{\circ} \mathrm{C}$ until further use.

\section{Cytokine Determination}

Cell supernatant and plasma were assayed for cytokine content using commercially available ELISA reagents for TNF $\alpha$, IL- 6 and IL-10 as described before (R\&D Systems, Abingdon, UK and BD Pharmingen, San Diego, CA, USA). Preliminary experiments showed $\mathrm{TNF} \alpha$ peak plasma levels at $1 \mathrm{~h}$ and IL-6 levels peak at $6 \mathrm{~h}$. Thereafter, all TNF $\alpha$ and IL-6 measurements in the D-Gal/LPS model were performed on plasma from controls, 1 and $6 \mathrm{~h}$ after treatment.

\section{Determination of APP}

Serum amyloid A protein (SAA) was measured by ELISA according to the manufacturer's instructions (Cytoscreen Immunoassay Kit, Biosource International, Camarillo, CA, USA). Serum amyloid P protein (SAP) was measured by a sandwich ELISA using sh- $\alpha$-mSAP as coating antibody, rb- $\alpha$-mSAP as secondary antibody (both Calbiochem, San Diego, CA, USA) and gt- $\alpha$-rblgG-alkaline-phosphatase (Sigma) as detecting antibody. Concentrations were calculated using mSAP-standard (Calbiochem, San Diego, CA, USA) as a reference.

\section{Northern Blot Analysis of Acute-Phase mRNAs}

Total hepatic RNA was isolated by the guanidine isothiocyanate method ${ }^{22}$ from livers of mice injected with D-Gal/LPS at 0, 1, 2, 9 and $24 \mathrm{~h}$. Northern blot analysis and hybridization with labelled cDNAs for serum amyloid A2 (SAA2) and SAA3, alpha-1-acid glycoprotein (AGP), haptoglobin (Hp), haemopexin (Hpx) and GAPDH was performed as described. ${ }^{17}$ Signals were quantified by phosphorimager analysis and normalized against the internal control GAPDH.

\section{Histological Investigation}

The Lung, liver and spleen sections were fixed in $10 \%$ neutral buffered formalin, embedded in paraffin blocks, sectioned at $4 \mu \mathrm{m}$, and stained with haematoxylin and eosin as described before. ${ }^{19}$ Sections from the liver and lungs of five mice per group were analysed.

\section{Statistical Analysis}

Analysis was performed using Student's $t$-tests, Mann-Whitney test and values of $P<0.05$ were considered significant. Survival were analysed by Kaplan-Meier test. Each experiment was repeated at least once to ensure reproducibility (see text and figures). 


\section{Results}

Enhanced Endotoxic Shock in D-Gal-Sensitized LIF-/- Mice

First, the effect of LPS ( $1 \mu \mathrm{g})$ on the circulating blood cells was investigated. At $6 \mathrm{~h}$, a significant leukopenia and thrombocytopenia was observed, which was more pronounced in the absence of LIF (Table 1).

The sensitivity of LIF-deficient mice to lethal endotoxic shock was then determined at three LPS doses (100, 10 and $1 \mathrm{ng}$ ) in D-Gal-sensitized mice. This well-established hypersensitivity model makes use of the sensitising effect of D-Gal increasing the lethal effect of LPS and greatly potentiating liver injury. ${ }^{17,23}$

LIF-/ - animals displayed more pronounced clinical symptoms of shock with huddled posture, piloerection, shivering, diarrhoea and body weight loss (Figure 1a), and succumbed between 6 and $12 \mathrm{~h}$ after administration, while wild-type mice showed a higher resistance to endotoxin and succumbed later (Figure 1b). The levels of alanine (ALT) and aspartate (AST) transaminases, enzyme markers of hepatocellular damage, were significantly increased in LIF-/ - mice at 6 and $24 \mathrm{~h}$ (Table 2).

Microscopic examination of the livers revealed vascular congestion, haemorrhage, hepatocellular vacuolization, fragmentation, pyknosis and necrosis $6 \mathrm{~h}$ after LPS injection, which was more prominent in LIF-/- mice than in the wild-type controls (Figure 2a). The lungs, which is another target organ of endotoxic shock, showed increased recruitment of neutrophils in LIF-/- mice (Figure 2b), which was confirmed by analysis of myeloperoxidase expression in the lung, which was significantly enhanced in the absence of LIF (data not shown).

Lastly, prior administration of recombinant LIF by the subcutaneous route (two injections at $1 \mu \mathrm{g}$ ) attenuated LPS-induced leukopenia in LIF-/ - mice (Table 3). Furthermore, the LPS-D-Gal induced increase of hepatic enzymes was also ameliorated in LIF-/ - and wild-type mice (Table 3). These data suggest that exogenous LIF can abrogate the enhanced LPS toxicity in the absence of LIF.

In summary, LPS had an augmented toxic effect on the haematological parameters, the lung and liver in the absence of LIF, which could be attenuated by exogenous LIF administration.

Table 1 Enhanced thrombocytopenia and leukopenia in LIF-/_ mice upon LPS injection

\begin{tabular}{|c|c|c|c|c|}
\hline & $L P S(\mu g)$ & Leukocytes & Lymphocytes & Thrombocytes \\
\hline LIF-/- & 0 & $12.7 \pm 1.8$ & $10.8 \pm 1.4$ & $467 \pm 38$ \\
\hline $\mathrm{LIF}+/+$ & 0 & $13.2 \pm 2.1$ & $11.4 \pm 1.1$ & $458 \pm 31$ \\
\hline LIF-/- & 1 & $4.2 \pm 0.5^{\S \S}$ & $2.9 \pm 0.3^{\circ}$ & $126 \pm 21^{\tau \S}$ \\
\hline $\mathrm{LIF}+/+$ & 1 & $8.6 \pm 0.7^{\circ}$ & $3.5 \pm 0.4$ & $291 \pm 18^{\circ}$ \\
\hline
\end{tabular}

Blood was taken at $6 \mathrm{~h}$ after LPS or saline injection. Values are mean \pm s.d. and represent 1000 cells/ $\mu$ l blood $(n=4-6$ mice per group).

${ }^{\top} P<0.05$ control vs LPS administration, ${ }^{\circledR} P<0.05$ in LPS-treated mice.
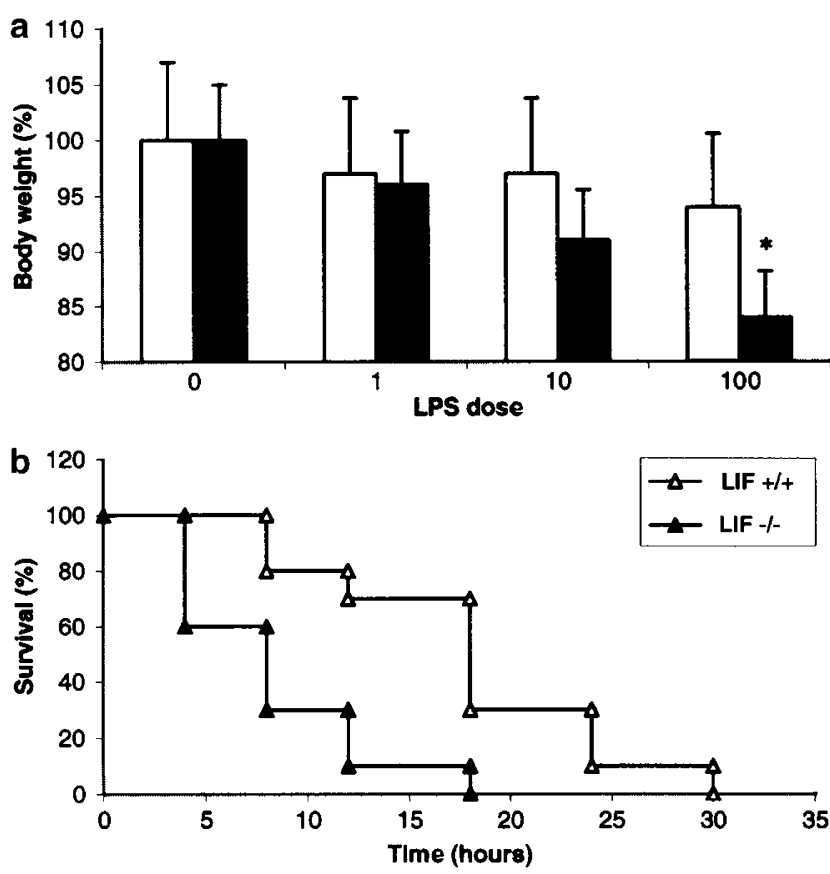

Figure 1 Increased body weight loss (a) and mortality (b) after LPS injection in D-Gal sensitized LIF-/- mice (closed bars or triangles) and LIF $+/+$ mice (open bars or triangles). Mice were injected with LPS (1-100 ng) together with D-Gal as described in Materials and methods; body weight was recorded at $12 \mathrm{~h}$, expressed as percentage of initial body weight. The relative body weights of the LIF-/ - mice at the $100 \mathrm{ng}$ LPS dose were significantly lower than LIF-/- mice $(P<0.05)$. Survival was recorded over $30 \mathrm{~h}$ after LPS (100 ng) and was significantly higher in $\mathrm{LIF}+/+$ mice $(n=10$ mice $)$.

Table 2 ALT and AST plasma levels at 6 and $12 \mathrm{~h}$ upon LPS-DGal injection in LIF+/+ and LIF-/ - mice

\begin{tabular}{|c|c|c|c|c|c|}
\hline & \multirow{2}{*}{$\begin{array}{l}\text { LPS } \\
\text { (ng) }\end{array}$} & \multicolumn{2}{|c|}{$6 h$} & \multicolumn{2}{|c|}{$12 \mathrm{~h}$} \\
\hline & & $L I F-/-$ & $L I F+/+$ & $L I F-/-$ & $L I F+/+$ \\
\hline \multirow[t]{3}{*}{ ALT (IU/ml) } & 1 & $56 \pm 4$ & $54 \pm 5$ & $368 \pm 84^{\S}$ & $102 \pm 14$ \\
\hline & 10 & $91 \pm 10$ & $84 \pm 10$ & $1499 \pm 189^{\S}$ & $487 \pm 87$ \\
\hline & 100 & $1037 \pm 132^{\S}$ & $898 \pm 121$ & - & - \\
\hline \multirow[t]{3}{*}{ AST (IU/ml) } & 1 & $118 \pm 12$ & $105 \pm 8$ & $868 \pm 114^{\S}$ & $254 \pm 45$ \\
\hline & 10 & $134 \pm 8$ & $118 \pm 11$ & $9123 \pm 234^{\S}$ & $436 \pm 87$ \\
\hline & 100 & $1091 \pm 91^{\S}$ & $931 \pm 76$ & - & - \\
\hline
\end{tabular}

Mice received $20 \mathrm{mg}$ D-Gal and LPS at 1 to $100 \mathrm{ng}$ per mouse. Values are mean \pm s.d. ${ }^{\S} P<0.05$ between experimental groups at given LPS dose ( $n=4-6$ mice per group).

The enhanced toxicity of LPS in LIF-/- mice might be due to increased proinflammatory cytokine production and altered acute-phase response.

\section{Increased Endotoxin-Induced TNF $\alpha$ and IL-6 Serum Levels in LIF - / - Mice}

We tested the possibility that cytokine secretion following LPS challenge was enhanced in the absence of LIF. Therefore, the serum concentrations of TNF $\alpha$ and IL-6 were determined after LPS 


\section{LIF-/-}
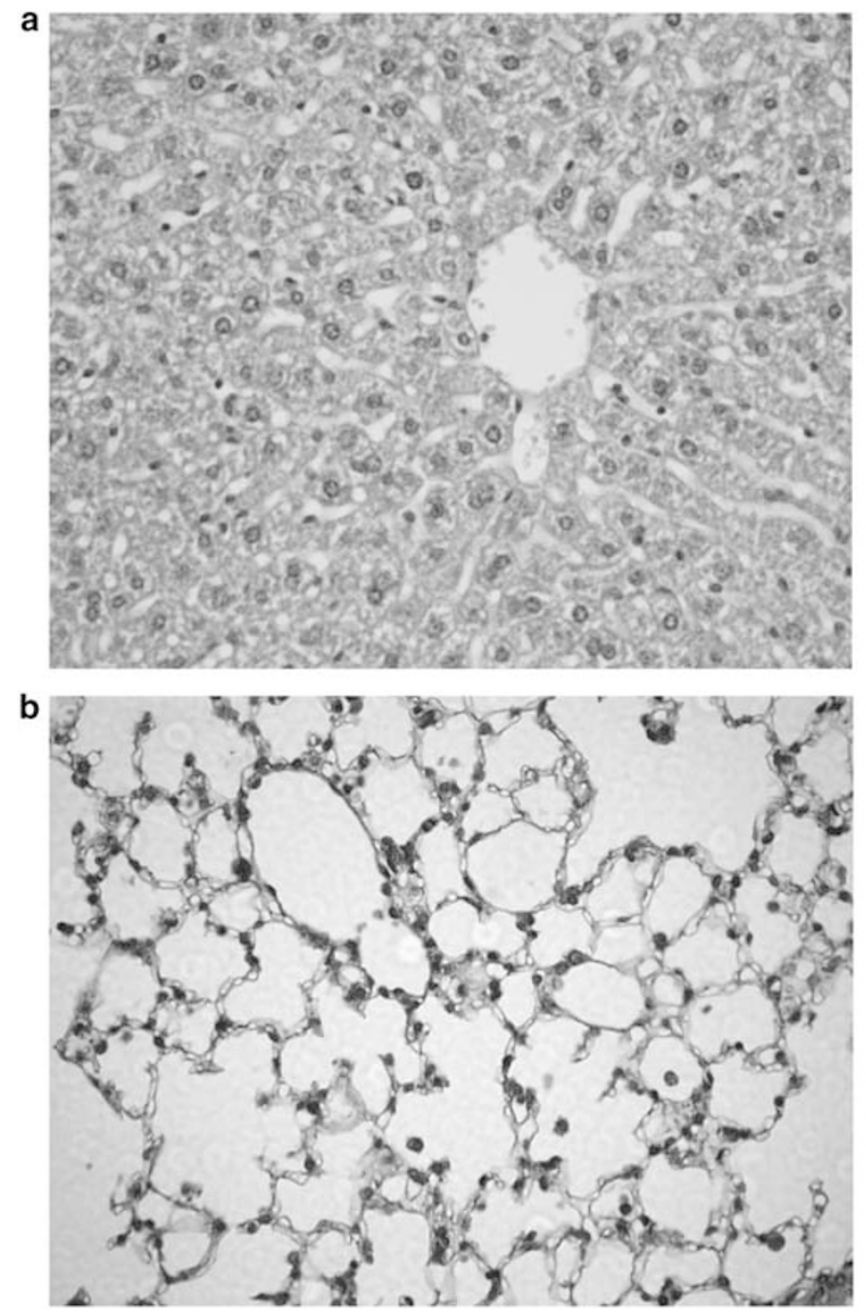

LIF-/-
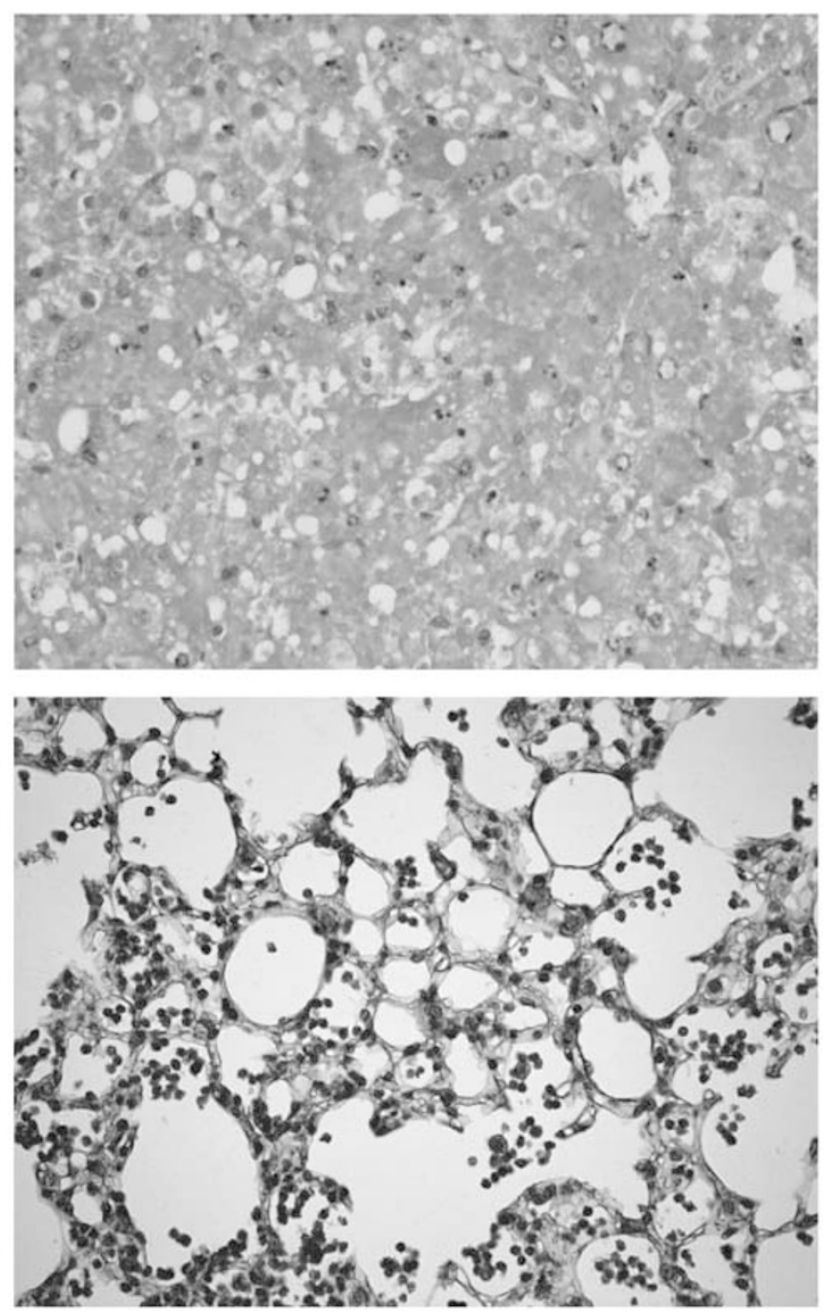

Figure 2 Enhanced liver damage and neutrophil recruitment into the lung induced by LPS injection in D-Gal-sensitized LIF-/- mice. (a) Hepatocellular necrosis induced by LPS ( $100 \mathrm{ng}$ ) injection in D-Gal-sensitized LIF-/ - mice as compared to LIF $+/+$ mice. Representative micrograph showing distinct necrosis, pyknosis, karyorrhexis and vascular congestion in LIF-/ - mice at $6 \mathrm{~h}$ after LPS-DGal injection, which was less pronounced in LIF $+/+$ mice $(n=6$ mice). (b) Augmented neutrophils recruitment induced by LPS (100 ng) injection in the lung of LIF $-/-$ mice as compared to LIF $+/+$ mice. Haematoxylin and eosin, $\times 280$ magnification $(n=6$ mice)

Table 3 Exogenous LIF attenuates leukopenia and liver damage in $\mathrm{LIF}+/+$ and $\mathrm{LIF}-/$ - mice

\begin{tabular}{|c|c|c|c|c|}
\hline \multirow[t]{2}{*}{ LPS (100 ng) } & \multicolumn{2}{|c|}{$L P S$} & \multicolumn{2}{|c|}{ LPS and LIF $(1 \mu g)$} \\
\hline & $L I F-/-$ & $L I F+/+$ & $L I F-/-$ & $L I F+/+$ \\
\hline Leukocytes & $5.4 \pm 0.6^{\S}$ & $8.2 \pm 0.9^{\S}$ & $9.7 \pm 1.6$ & $10.6 \pm 1.9$ \\
\hline ALT (IU/ml) & $863 \pm 91^{\S}$ & $498 \pm 121^{\S}$ & $175 \pm 64$ & $170 \pm 92$ \\
\hline AST (IU/ml) & $851 \pm 91^{\S}$ & $460 \pm 76^{\S}$ & $163 \pm 58$ & $124 \pm 76$ \\
\hline
\end{tabular}

Mice received $20 \mathrm{mg}$ D-Gal and LPS at $100 \mathrm{ng}$ per mouse, LIF $(1 \mu \mathrm{g})$ was given 6 and $1 \mathrm{~h}$ before s.c. Mice were bled at $6 \mathrm{~h}$ for haematological and serum chemistry analysis. Values are mean \pm s.d. ${ }^{\S} P<0.05$ between the groups receiving LPS vs LPS/LIF $(n=4-6$ mice per group).

administration $(10 \mu \mathrm{g})$. In both LIF - / - and LIF + / + mice, TNF $\alpha$ and IL-6 serum concentrations peaked at 1 and at $3 \mathrm{~h}$, respectively. LIF-deficiency resulted in significant higher serum $\mathrm{TNF} \alpha$ levels, which persisted for up to $6 \mathrm{~h}$ after LPS injection (Figure 3a). In contrast, wild-type mice had no detectable TNF $\alpha$ at $3 \mathrm{~h}$. Similar findings were obtained with IL-6 showing higher and protracted IL-6 serum levels in $\mathrm{LIF}-/$ - mice than $\mathrm{LIF}+/+$ mice (Figure $3 \mathrm{~b}$ ). We further tested the effect of the LPS dose in D-Galsensitized mice. TNF $\alpha$ serum level at $1 \mathrm{~h}$ was significantly elevated already at the $10 \mathrm{ng}$ LPS dose, while IL-6 levels at $3 \mathrm{~h}$ were only induced at the 100ng dose (data not shown).

Therefore, endotoxin-induced $\mathrm{TNF} \alpha$ and IL-6 serum levels were significantly increased and may have a protracted course in LIF-/ - mice.

\section{Decreased Endotoxin-Induced IL-10 Production in LIF_/_ Mice}

IL-10 is induced by LPS in macrophages/monocytes in vitro and in vivo in mice ${ }^{24,25}$ and in septicaemia. ${ }^{26}$ 

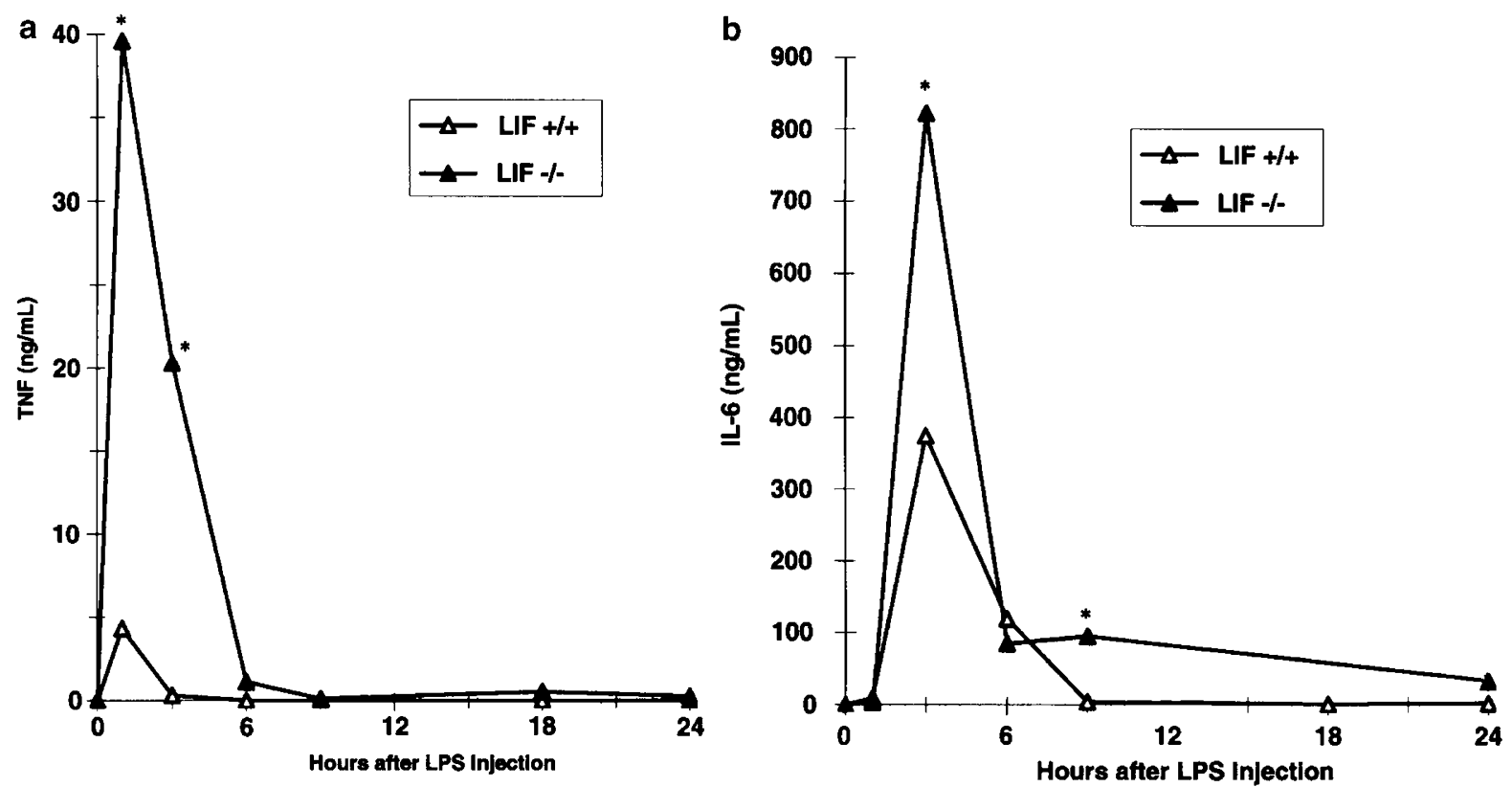

Figure 3 Time dependent changes of TNF $\alpha$ (a) and IL-6 (b) serum levels in LIF-/ - mice upon LPS injection (10 $\mu \mathrm{g})$. Peak TNF $\alpha$ and IL-6 serum levels at 1 and $3 \mathrm{~h}$, respectively, were significantly higher in LIF $-/$ - mice (black triangle) than in LIF $+/+$ mice (open triangle, $\left.{ }^{*} P<0.05\right)$. Mean values \pm s.d. are given $(n=5$ mice $)$.
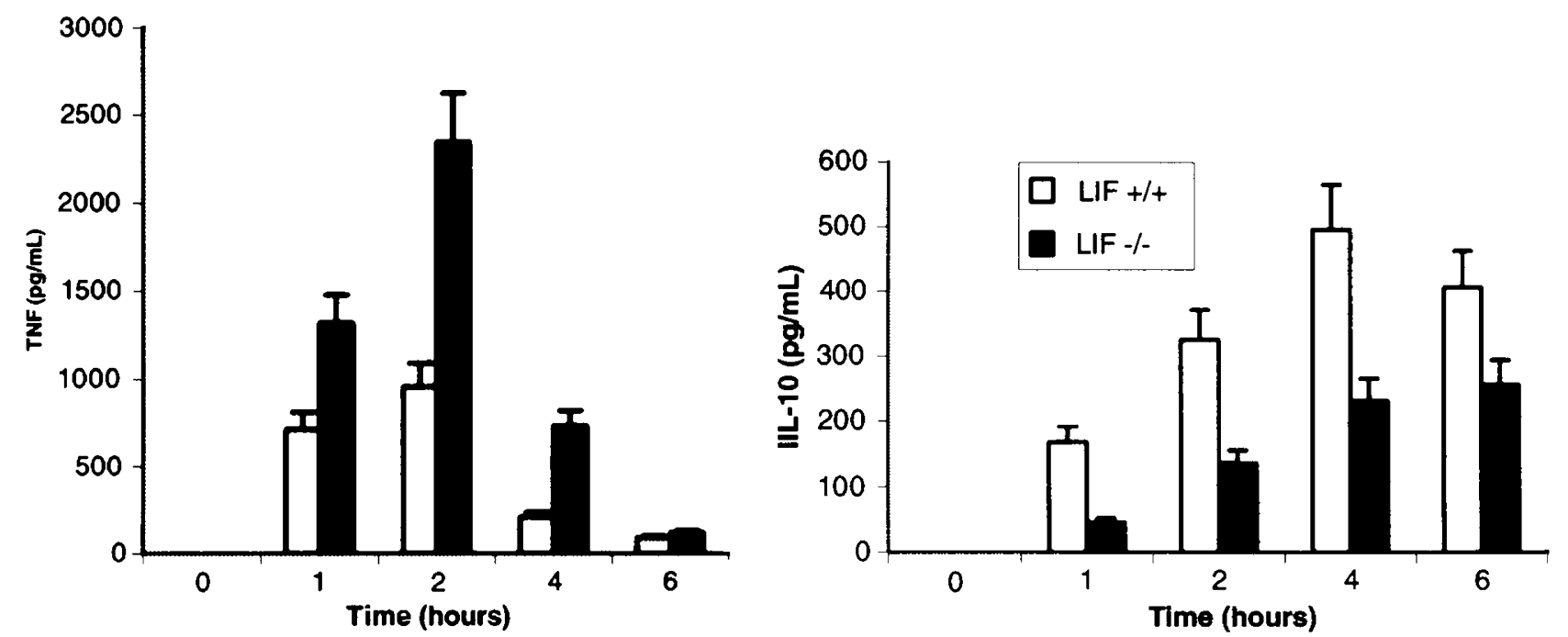

Figure 4 Increased TNF and reduced IL-10 production in LPS stimulated BMDM from LIF-/- mice. BMDM from LIF-/- mice (black bars) than in LIF + / + mice (open bars) were stimulated with $100 \mathrm{ng} / \mathrm{ml} \mathrm{LPS}$ and the cell supernatant was assessed for TNF and IL-10 at 1, 2, 4 and $6 \mathrm{~h}$ by ELISA. Mean values \pm s.d. are given, ${ }^{*} P<0.05$. Representative results from three independent experiments.

There is evidence that IL-10 downregulates TNF $\alpha$ production. ${ }^{25,27}$ Therefore, we asked whether endogenous LIF affects IL-10 production. First, we tested $\mathrm{TNF} \alpha$ and IL-10 production by bone marrow-derived macrophages. LPS-induced activation of macrophages in the absence of LIF resulted in enhanced production of $\mathrm{TNF} \alpha$, and diminished IL-10 secretion as compared to wild-type macrophages (Figure 4). Then, we tested the effect of LPS administration on IL-10 serum levels in vivo. In accordance with the effect on macrophages, the IL-10 levels were significantly reduced in LIF-/ - mice upon LPS injection (Figure 5).
Therefore, the data suggest that in the absence of endogenous LIF LPS-induced TNF $\alpha$ production was augmented, which may be related to the diminished production of IL-10, a known regulator of $\mathrm{TNF} \alpha$ production.

\section{Decreased Basal and Enhanced LPS-Induced APP in the Absence of LIF}

The acute-phase response has been shown to be protective in infection and endotoxic shock. The sensitizing effect of the LPS/D-Gal-model is likely 


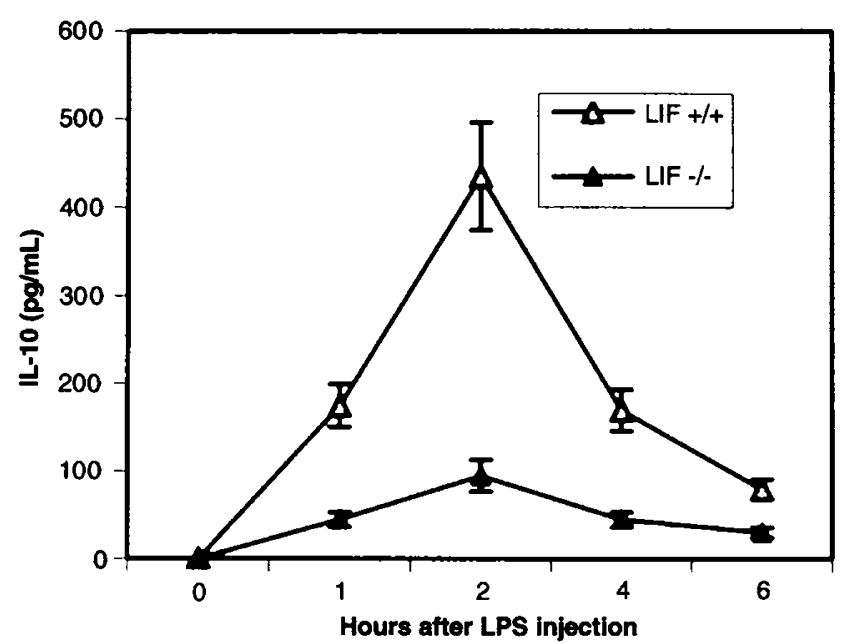

Figure 5 Decreased IL-10 plasma levels upon LPS injection in the absence of LIF LPS $(10 \mu \mathrm{g})$ was injected i.p. in LIF $+/+$ and LIF-/ - mice and serum was taken after LPS injection and serum was analysed by ELISA for IL-10 levels. Mean values \pm s.d. are given, ${ }^{*} P<0.05(n=6-8$ mice $)$.
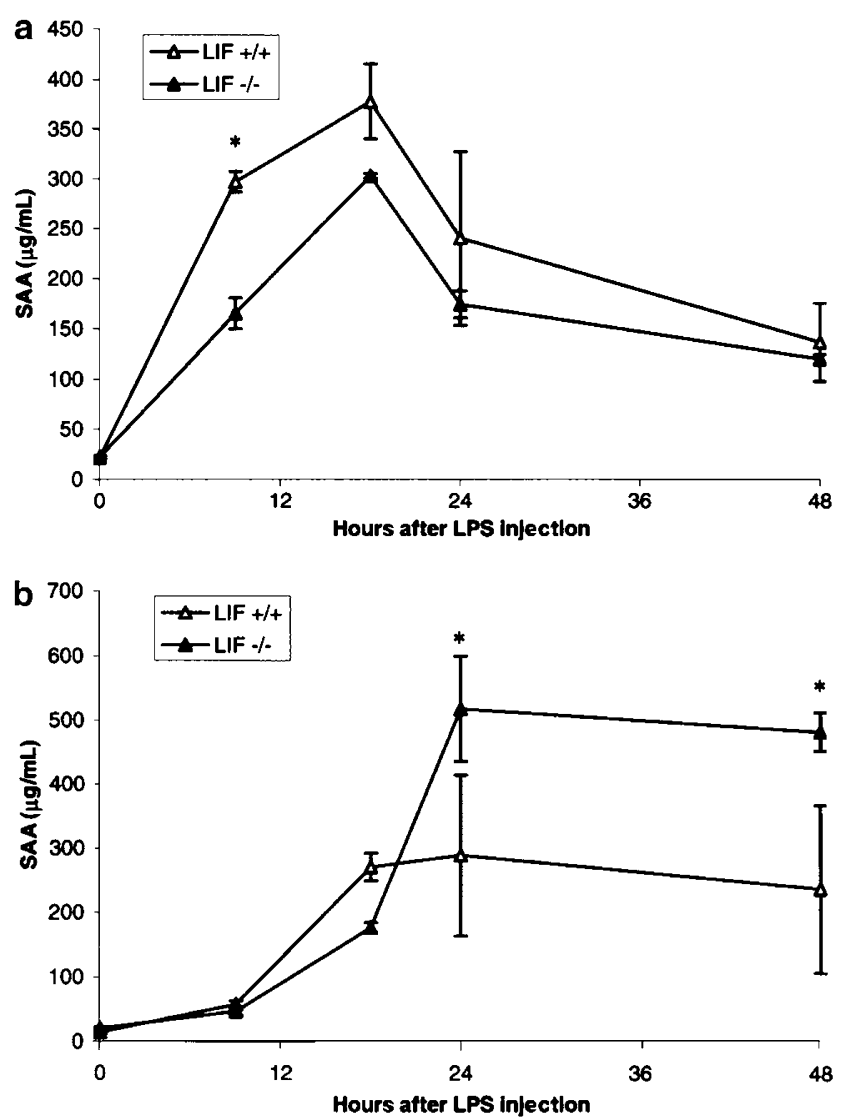

Figure 6 Low basal, but augmented SAA and SAP serum levels in LIF $-/$ - mice upon LPS $(10 \mu \mathrm{g})$ injection. SAA (a) and SAP (B) serum levels were determined over 2 days by ELISA in LIF-/mice (closed triangle) and LIF $+/+$ mice (open triangle) as described under Materials and methods. SAA levels were higher in LIF-/ - mice over $24 \mathrm{~h}$ upon LPS injection, while SAP levels were slightly delayed at $18 \mathrm{~h}$, but augmented at 24 and $48 \mathrm{~h}$ in LIF-/ - mice. The data were compared with the nonparametric Mann-Whitney test $\left({ }^{*} P<0.05\right)$. Mean values \pm s.d. are given $(n=5$ mice). due to an inhibition of acute-phase reactants in the liver by a global hepatic synthesis inhibitor 23. The two major APP in mice, SAA and SAP were measured before and after LPS administration. The LIF-/ - mice exhibited slightly lower basal serum levels of both proteins, which were, however, not significantly different from LIF $+/+$ mice. Upon LPS injection, SAA was rapidly induced, and the serum concentrations were initially significantly higher in LIF-/ - mice (Figure 6a). SAP levels were initially lower in LIF-/- mice, but significantly superior at 24 and $48 \mathrm{~h}$ to those of LIF + / + mice, which could be due to the sustained and elevated IL-6 levels (Figure 6b). It has been previously shown that cytokine-induced changes seen of APP secretion are in part reflected in mRNA expression. Northern blot analysis of RNA levels of SAA2, SAA3, Hp, AGP and HPX in the liver revealed a distinctive lower basal mRNA level in LIF-/ - mice (Figure 7). However, mRNA levels for all five genes were induced by LPS to a similar extent in both types of mice except for heightened SAA3 levels at 2 and $9 \mathrm{~h}$ postinjection in LIF-/ - mice (see Figure 7 and Table 4 for the quantification by densitometry). Therefore, steady-state transcripts and expression of APP, but not LPS-induced transcription or expression was lower, which might explain in part the heightened sensitivity of the LIF-/- mice.

\section{Discussion}

Our data demonstrate a critical protective role of endogenous LIF in endotoxin-induced pathology. Endotoxin injection into D-Gal-sensitized LIF-/mice resulted in enhanced signs of shock, including a huddled posture, piloerection, shivering, diarrhoea, body weight loss and death. Death was preceded by leukopenia, and thrombocytopenia, enhanced neutrophil recruitment into the lung and hepatocellular damage. Hepatotoxicity of LIF-/mice correlated with a 10-fold increased and protracted TNF $\alpha$ and IL-6 serum levels, reduced

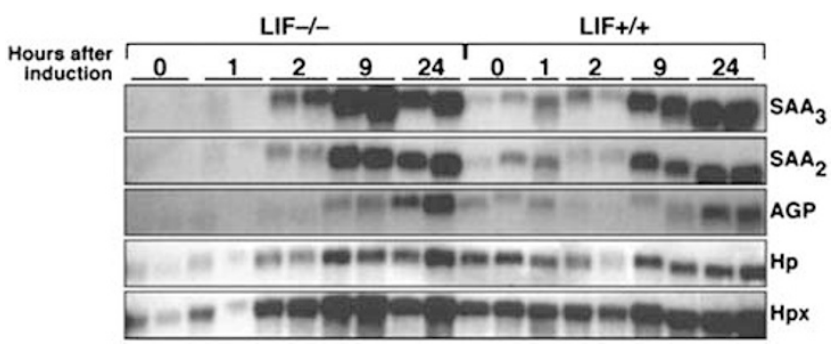

Figure 7 Acute-phase response transcripts in the liver of LIF-/ and mice upon LPS injection (10 $\mu \mathrm{g}, 0-24 \mathrm{~h})$. RNA was extracted and hybridized with probes for SAA3, SAA2, AGP, Hp and Hpx as described under Materials and methods. While the basal level of acute-phase transcripts was significantly lower in LIF-/- mice, there was no difference at the transcriptional level upon LPS injection. The densitometric analysis of the gel is given in Table 2 $(P<0.05)$. Mean values are given $(n=5)$. 
Table 4 Quantification of acute phase protein mRNA levels upon LPS injection

\begin{tabular}{|c|c|c|c|c|c|c|c|c|}
\hline \multirow[t]{2}{*}{ Time (h) } & \multicolumn{2}{|c|}{$H P$} & \multicolumn{2}{|c|}{$A G P$} & \multicolumn{2}{|c|}{$S A A 2$} & \multicolumn{2}{|c|}{$S A A 3$} \\
\hline & $L I F+/+$ & $L I F-/-$ & $L I F+/+$ & $L I F-/-$ & $L I F+/+$ & $L I F-/-$ & $L I F+/+$ & $L I F-/$ \\
\hline 0 & 49.6 & 11.9 & 28.3 & 5.5 & 175 & 6.2 & 159 & 2.3 \\
\hline 2 & 35.7 & 26.3 & 12.4 & 11.5 & 189 & 194 & 228 & 349 \\
\hline 9 & 59.7 & 70.1 & 34.1 & 47.7 & 727 & 708 & 841 & 1896 \\
\hline 24 & 53.0 & 49.3 & 76.9 & 66.8 & 998 & 910 & 1182 & 774 \\
\hline
\end{tabular}

Densitometric analysis of hepatic transcripts as arbitrary units, mean values $(n=2)$. The values prior the LPS injections (in bold) are distinctly lower, while SAA3 levels at 2 and $9 \mathrm{~h}$ post-injection are increased in the LIF-/ - mice.

IL-10 production and diminished basal expression of APP.

These results contradict previously published results ${ }^{15}$ where passive immunization with a polyclonal anti-LIF antiserum protected mice from LPSinduced shock. However, the functional properties of this rabbit IgG were not characterized. It is quite possible that the antiserum used increased the bioavailability of LIF rather causing its neutralization. ${ }^{15}$ This interpretation would be coherent with our results, which are consistent with the data showing that an injection of LIF prior to LPS protected the mice from endotoxic shock. ${ }^{11}$ Furthermore, we were able to attenuate LPS toxicity in LIF-/ - mice by exogenous LIF.

The present results support the notion that endogenous LIF released during septic shock acts as an early mediator to dampen the inflammatory response. ${ }^{14,28}$ The sustained systemic presence of $\mathrm{TNF} \alpha$ in LIF-/ - mice suggests that LIF could also have a regulatory effect on TNF $\alpha$ either at the level of transcription, translation or clearance. It has been shown that $\mathrm{TNF} \alpha$ can substitute for endotoxin in inducing lethal endotoxemia in hypersensitivity models. ${ }^{29,30}$ Inhibition of $\mathrm{TNF} \alpha$ synthesis or release,$^{31}$ action and/or binding either through passive immunization $^{32}$ or interruption of its signalling pathway, as in the TNFRp55-deficient mice, ${ }^{33}$ improves survival rates to endotoxic shock. In a cutaneous model of inflammation, LIF had an antiinflammatory effect and it was shown to have regulatory roles on several cytokines including IL$1 \beta$ and IL-6. ${ }^{14}$ The observed prolonged and elevated serum concentration of IL-6 is most probably not a direct consequence of the LIF-deficiency, and may be related to increased TNF $\alpha$ activating IL-6 expression through the NF- $\kappa \mathrm{B}$ signal transduction pathway. $^{33}$ Interestingly, a defective hypothalamicpituitary-adreno-cortical system in response to inflammatory stress with elevated IL- 6 and TNF $\alpha$ levels has been reported in LIF-/- mice. ${ }^{3,28}$ This defect has been associated with reduced ACTH and corticosterone levels, and invites the hypothesis that LIF deficiency might be corrected in part by steroid replacement. Lastly, we asked whether the cytokine regulator IL-10 is regulated in a LIF-dependent manner. We show here that LPS-induced IL-10 synthesis is reduced in LIF-/ - mice as compared to wild-type mice. The decreased IL-10 response in vitro and in vivo to LPS in LIF-/ - mice is associated with increased $\mathrm{TNF} \alpha$ levels. These results are consistent with studies showing a protective effect of IL-10 on endotoxic shock and TNF $\alpha$ expression. ${ }^{27}$ Therefore, the data suggest that endogenous LIF favours the expression of IL-10 and thereby restricts $\mathrm{TNF} \alpha$ production. In the absence of LIF, the synthesis of IL-10 is reduced allowing a largely unrestricted $\mathrm{TNF} \alpha$ production and endotoxic shock.

APP have been suggested to be protective in endotoxic shock. ${ }^{18,34} \mathrm{LIF}-/$ - mice are capable to produce APP, although the response is altered. The mRNA transcript levels of APP genes are at lower basal levels in LIF-/- mice and the basal serum protein levels are slightly reduced. However, both transcripts and proteins were inducible and able to respond the same or even higher levels. The sustained protein expression SAP and to a lesser extent of SAA is probably due to the elevated IL-6 levels, which is a major inducer of APP synthesis. These results suggest that LIF plays a role in the establishment of normal base levels and in the induction of the early APP. As mortality in this endotoxic shock model usually appears within the first $10 \mathrm{~h}$, the increased response of the APP occurs too late to have a mitigating effect.

Previously it has been shown that a single i.v. dose of LIF is able to protect mice from the lethal effect of LPS $^{12}$ and live E. coli. ${ }^{11}$ The protection by prior administration of LIF does not necessarily have to be the same mechanism as the observed sensitization in the absence of LIF. It has been suggested that induction of the APP plays a central role in establishing protection. Similar results were achieved in experiments with prior injection of TNF $\alpha,{ }^{35}$ IL- $1 \alpha,{ }^{36}$ IL- $1 \beta,{ }^{37}$ IL- ${ }^{38-40}$ and IL-10. ${ }^{27}$ In all these studies, a decrease in $\mathrm{TNF} \alpha$ production was observed, together with the ability to induce the synthesis of APP in the liver as having an important role of the involvement of the acute-phase response in protecting against lethal endotoxemia.

Interestingly, in IL-6-deficient mice, a similar increase in $\mathrm{TNF} \alpha$ induction was reported as in LIF-/ - mice. ${ }^{41}$ It seems that LIF and IL-6 are able to compensate for each other's absence and induce a 
similar set of APP. This shows again how closely related the shared biological activities of these two cytokines are, which may be due to the fact that both use the same signal transducing subunit gp130 receptor, which converts the low-affinity gp130 receptor to a high-affinity receptor by heterodimerization to a separate receptor subunits. The possible explanation suggested for the response in IL-6deficient mice is that the absence of the negative IL-6 feedback mechanism is responsible for the heightened TNF $\alpha$ level, because IL-6 is able to inhibit TNF $\alpha$ transcription, ${ }^{39,40}$ but does not explain the findings in our model, as IL-6 serum concentrations are also elevated. This is perhaps a further indication that the observed sensitivity is due to the lower concentrations of APP during the onset of endotoxemia. In addition, different individual APPs have shown to be protective in endotoxin-induced shock. These have included the third component of complement (C3), ${ }^{42} \alpha 1$-acid glycoprotein (possibly through its platelet aggregation inhibitory activity), ${ }^{34}$ and $\alpha 1$-antitrypsin with its inhibition of serine proteinases preventing the proteolytic cleavage of the membrane-bound form of TNF $\alpha$ upon stimulation with LPS. ${ }^{43}$

In conclusion, our results show that LIF induction is necessary for a normal host reaction against endotoxin and probably other pathogen-derived molecules released in sepsis. Endogenous LIF mitigates the early endotoxic shock response by enhancing IL-10 and inhibiting TNF $\alpha$ and IL-6 synthesis and release, and inducing an acute-phase response.

\section{Acknowledgements}

Drs Ken-Ichi Yamamoto, Heinz Baumann, Ursula Müller Eberhard for the kind gift of plasmids and Professor Jack Gauldie for helpful suggestions. Silvia and Bruno Schnyder were supported by the Biomedical Research Foundation and the Swiss National Foundation, and the Le Studium, Orleans.

\section{References}

1 Metcalf D. The leukemia inhibitory factor (LIF). Int J Cell Cloning 1991;9:95-108.

2 Hilton DJ. LIF: lots of interesting functions. Trends Biochem Sci 1992;17:72-76.

3 Chesnokova V, Melmed S. Minireview: neuro-immuno-endocrine modulation of the hypothalamic-pituitary-adrenal (HPA) axis by gp130 signaling molecules. Endocrinology 2002;143:1571-1574.

4 Alexander HR, Billingsley KG, Block MI, et al. D-factor/ leukaemia inhibitory factor: evidence for its role as a mediator in acute and chronic inflammatory disease. Cytokine 1994;6:589-596.

5 Heinrich PC, Behrmann I, Haan S, et al. Principles of interleukin (IL)-6-type cytokine signalling and its regulation. Biochem J 2003;374:1-20.
6 Gadient RA, Patterson PH. Leukemia inhibitory factor, interleukin 6, and other cytokines using the GP130 transducing receptor: roles in inflammation and injury. Stem Cells 1999;17:127-137.

7 Gough NM, Williams RL, Hilton DJ, et al. LIF: a molecule with divergent actions on myeloid leukaemic cells and embryonic stem cells. Reprod Fertil Dev 1989;1:281-288.

8 Waring P, Wycherley K, Cary D, et al. Leukemia inhibitory factor levels are elevated in septic shock and various inflammatory body fluids. J Clin Invest 1992;90:2031-2037.

9 Waring PM, Waring LJ, Metcalf D. Circulating leukemia inhibitory factor levels correlate with disease severity in meningococcemia. J Infect Dis 1994;170:1224-1228.

10 Block MI, Fraker DL, Strassmann G, et al. Endogenous D-factor activity partially mediates the toxic but not the therapeutic effects of tumor necrosis factor. Int J Cancer 1995;63:245-249.

11 Waring PM, Waring LJ, Billington T, et al. Leukemia inhibitory factor protects against experimental lethal Escherichia coli septic shock in mice. Proc Natl Acad Sci USA 1995;92:1337-1341.

12 Alexander HR, Wong GG, Doherty GM, et al. Differentiation factor/leukemia inhibitory factor protection against lethal endotoxemia in mice: synergistic effect with interleukin 1 and tumor necrosis factor. J Exp Med 1992;175:1139-1142.

13 Ulich TR, Fann MJ, Patterson PH, et al. Intratracheal injection of LPS and cytokines. V. LPS induces expression of LIF and LIF inhibits acute inflammation. Am J Physiol 1994;267:L442-L446.

14 Zhu M, Oishi K, Lee SC, et al. Studies using leukemia inhibitory factor (LIF) knockout mice and a LIF adenoviral vector demonstrate a key anti-inflammatory role for this cytokine in cutaneous inflammation. J Immunol 2001;166:2049-2054.

15 Block MI, Berg M, McNamara MJ, et al. Passive immunization of mice against Dfactor blocks lethality and cytokine release during endotoxemia. J Exp Med 1993;178:1085-1090.

16 Stewart CL, Cullinan E. LIF and related cytokines in the regulation of mammalian development. Ann NY Acad Sci 1995;762:29-30.

17 Galanos C, Freudenberg MA, Reutter W. Galactosamine-induced sensitization to the lethal effects of endotoxin. Proc Natl Acad Sci USA 1979;76:59395943.

18 Alcorn JM, Fierer J, Chojkier M. The acute-phase response protects mice from D-galactosamine sensitization to endotoxin and tumor necrosis factor-alpha. Hepatology 1992;15:122-129.

19 Car BD, Eng VM, Schnyder B, et al. Interferon gamma receptor deficient mice are resistant to endotoxic shock. J Exp Med 1994;179:1437-1444.

20 Escary JL, Perreau J, Dumenil D, et al. Leukaemia inhibitory factor is necessary for maintenance of haematopoietic stem cells and thymocyte stimulation. Nature 1993;363:361-364.

21 Muller M, Eugster HP, Le Hir M, et al. Correction or transfer of immunodeficiency due to TNF-LT alpha deletion by bone marrow transplantation. Mol Med 1996;2:247-255.

22 Chomczynski P, Sacchi N. Single-step method of RNA isolation by acid guanidinium thiocyanate-phenolchloroform extraction. Anal Biochem 1987;162:156159. 
23 Keppler D, Lesch R, Reutter W, et al. Experimental hepatitis induced by D-galactosamine. Exp Mol Pathol 1968;9:279-290.

24 Marchant A, Bruyns C, Vandenabeele P, et al. The protective role of interleukin-10 in endotoxin shock. Prog Clin Biol Res 1994;388:417-423.

25 Shakhov AN, Woerly G, Car BD, et al. Interferongamma enhances tumor necrosis factor-alpha production by inhibiting early phase interleukin-10 transcription. Eur Cytokine Netw 1996;7:741-750.

26 Marchant A, Deviere J, Byl B, et al. Interleukin-10 production during septicaemia. Lancet 1994;343: 707-708.

27 Marchant A, Bruyns C, Vandenabeele P, et al. Interleukin-10 controls interferon-gamma and tumor necrosis factor production during experimental endotoxemia. Eur J Immunol 1994;24:1167-1171.

28 Chesnokova V, Kariagina A, Melmed S. Opposing effects of pituitary leukemia inhibitory factor and SOCS-3 on the ACTH axis response to inflammation. Am J Physiol Endocrinol Metab 2002;282:E1110E1118.

29 Lehmann V, Freudenberg MA, Galanos C. Lethal toxicity of lipopolysaccharide and tumor necrosis factor in normal and D-galactosamine-treated mice. J Exp Med 1987;165:657-663.

30 Tiegs G, Wolter M, Wendel A. Tumor necrosis factor is a terminal mediator in galactosamine/endotoxin-induced hepatitis in mice. Biochem Pharmacol 1989; 38:627-631.

31 Mohler KM, Sleath PR, Fitzner JN, et al. Protection against a lethal dose of endotoxin by an inhibitor of tumour necrosis factor processing. Nature 1994;370: 218-220.

32 Beutler B, Milsark IW, Cerami AC. Passive immunization against cachectin/tumor necrosis factor protects mice from lethal effect of endotoxin. Science 1985;229: 869-871.

33 Pfeffer K, Matsuyama T, Kundig TM, et al. Mice deficient for the $55 \mathrm{kd}$ tumor necrosis factor receptor are resistant to endotoxic shock, yet succumb to $L$. monocytogenes infection. Cell 1993;73:457-467.

34 Libert C, Brouckaert P, Fiers W. Protection by alpha 1-acid glycoprotein against tumor necrosis factor-induced lethality. J Exp Med 1994;180:15711575.

35 Sheppard BC, Fraker DL, Norton JA. Prevention and treatment of endotoxin and sepsis lethality with recombinant human tumor necrosis factor. Surgery 1989;106:156-161; discussion 161-152.

36 Alexander HR, Doherty GM, Fraker DL, et al. Human recombinant interleukin-1 alpha protection against the lethality of endotoxin and experimental sepsis in mice. J Surg Res 1991;50:421-424.

37 Vogels MT, Cantoni L, Carelli M, et al. Role of acutephase proteins in interleukin-1-induced nonspecific resistance to bacterial infections in mice. Antimicrob Agents Chemother 1993;37:2527-2533.

38 Barton BE, Jackson JV. Protective role of interleukin 6 in the lipopolysaccharide-galactosamine septic shock model. Infect Immun 1993;61:1496-1499.

39 Aderka D, Le JM, Vilcek J. IL-6 inhibits lipopolysaccharide-induced tumor necrosis factor production in cultured human monocytes, U937 cells, and in mice. J Immunol 1989;143:3517-3523.

40 Xing Z, Gauldie J, Cox G, et al. IL-6 is an antiinflammatory cytokine required for controlling local or systemic acute inflammatory responses. J Clin Invest 1998;101:311-320.

41 Fattori E, Cappelletti M, Costa $\mathrm{P}$, et al. Defective inflammatory response in interleukin 6-deficient mice. J Exp Med 1994;180:1243-1250.

42 Quezado ZM, Hoffman WD, Winkelstein JA, et al. The third component of complement protects against Escherichia coli endotoxin-induced shock and multiple organ failure. J Exp Med 1994;179:569-578.

43 Niehorster M, Tiegs G, Schade UF, et al. In vivo evidence for protease-catalysed mechanism providing bioactive tumor necrosis factor alpha. Biochem Pharmacol 1990;40:1601-1603. 